\title{
Materials matter in phosphorus sustainability
}

\author{
By Jacob L. Jones, Yaroslava G. Yingling, Ian M. Reaney, and Paul Westerhoff
}

$\mathrm{T}$ his year marks the 350th anniversary of the discovery of phosphorus by German alchemist Hennig Brandt. ${ }^{1}$ As element 15 in the periodic table, phosphorus is known to researchers for its luminescent and reactive characteristics in elemental form, as a dopant in semiconductors, as a key constituent in nerve agents and industrial detergents, ${ }^{2}$ and, most recently, in its two-dimensional (2D) form, phosphorene (a black phosphorus allotrope). However, its role in biology and agriculture has more foundational implications for society. ${ }^{3}$ It is part of the backbone of DNA. Because of its central role in biological energy transfer processes, phosphorus is also an essential component in fertilizers underpinning the productivity of global food systems, enabling society to sustain Earth's growing population.

Unfortunately, myriad cross-disciplinary challenges pervade the life cycle of phosphorus, from its sources and availability to its application and disposal or reuse. ${ }^{4,5}$ The challenges around the phosphorus life cycle are so complex that they have been termed a "wicked problem"; 6,7 the problems are intractable, contested, and plagued by a high degree of uncertainty. These can be more deeply appreciated by noting that challenges in the phosphorus life cycle span 17 orders of magnitude in length scale-from the atomic scale of elemental phosphorus and the orthophosphate ion to farms and farmers, phosphate mines, and lakes to global economics and public policy (see Figure 1). ${ }^{89}$ These length scales involve diverse stakeholders with sometimes competing priorities.

\section{The phosphorus life cycle}

The challenges for phosphorus start at the cradle. Presently, phosphorus is a nonrenewable resource extracted dominantly from phosphate mines (Figure 1j). The quantity of phosphorus mined and produced is large: In 2018, 270 million tonnes $(\mathrm{Mt})$ of phosphate rock (mostly apatites [i.e., $\left.\mathrm{Ca}_{5}\left(\mathrm{PO}_{4}\right)_{3}(\mathrm{~F}, \mathrm{Cl}, \mathrm{OH}, \mathrm{Br})\right]$ were used in global production, providing $66 \mathrm{Mt}$ of $\mathrm{P}_{2} \mathrm{O}_{5}$ (used in fertilizers). ${ }^{10}$ By comparison, the global mining production of aluminum and copper were most recently reported to be $46 \mathrm{Mt}$ and $16 \mathrm{Mt}$ per year, respectively. ${ }^{11}$ Although China produces more than $50 \%$ of the world's current supply of phosphorus, the world's reserves of phosphate rock are concentrated, with $70 \%$ in Morocco and the Western Sahara. ${ }^{10}$

At current rates of use, the United States and the EU are expected to run out of their domestic phosphorus supplies within the next generation, significantly increasing their dependence on imports. The concentration of supplies and reserves can result in price fluctuations because of economic uncertainty or political unrest, as evidenced in 2008 when the price of phosphate rock spiked approximately $800 \%$, from USD $\$ 50$ / tonne to USD\$430/tonne. ${ }^{12}$ Thus, phosphorus is a low-cost yet large-volume critical resource with an uncertain future supply.

Approximately $90 \%$ of mined phosphate is used for fertilizers, ${ }^{13}$ where phosphorus serves as an essential element for plant growth (Figure 1f, h). In fertilizers, phosphorus is applied in combination with other nutrients, such as nitrogen and potassium, and in different forms such as finely ground rock phosphate, triple superphosphate $\left(\mathrm{Ca}\left(\mathrm{H}_{2} \mathrm{PO}_{4}\right)_{2} \cdot \mathrm{H}_{2} \mathrm{O}\right)$, and liquid polyphosphates (e.g., ammonium polyphosphate or $\left.\left[\mathrm{NH}_{4} \mathrm{PO}_{3}\right]_{\mathrm{n}}(\mathrm{OH})_{2}\right)$.
Phosphorus must be in a biologically available form to be taken up by plants, and the most bioavailable form of phosphorus is aqueous orthophosphate $\left(\mathrm{H}_{2} \mathrm{PO}_{4}^{-} / \mathrm{HPO}_{4}{ }^{2-} / \mathrm{PO}_{4}{ }^{3-}\right)$ (Figure $\left.1 \mathrm{~b}\right)$. The amount of phosphorus in fertilizers that is bioavailable depends on many factors, including the $\mathrm{pH}$ of soil and water, microbial activity, sorption of orthophosphates to soil metal oxides and hydroxides, complexation with aqueous ligands, and polyphosphate polymerization. The amount of phosphorus used by organisms also depends upon the bioavailability of nitrogen, and the Redfield ratio of nitrogen/phosphorus aids in understanding systems that are either nitrogen- or phosphorus-limited.

While nitrogen-based fertilizers can be mined, engineered processes (e.g., Haber-Bosch) cost-effectively convert atmospheric $\mathrm{N}_{2}$ into ammonia, which serves as the building block for most modern nitrogen fertilizers. ${ }^{14}$ Thus, unlike phosphorus, there are endless and geographically independent sources of nitrogen. Because of the specificity of bioavailable forms of phosphorus and the low mobility of phosphorus through soils, plants do not take up most of the phosphorus that is applied to farmlands. In fact, only $20 \%$ of the phosphorus mined for food production is ultimately incorporated into the human $\operatorname{diet}^{3}$ The remaining agricultural phosphorus takes one of two main pathways: it builds up in soils, integrates into secondary nonfood products and, combined with animal waste (Figure $1 \mathrm{~g})$, contributes to a so-called "legacy phosphorus" problem, or it is lost to surface waters, where it contributes to eutrophication, or algal blooms and related hypoxia of marine life (Figure 1i). As a 


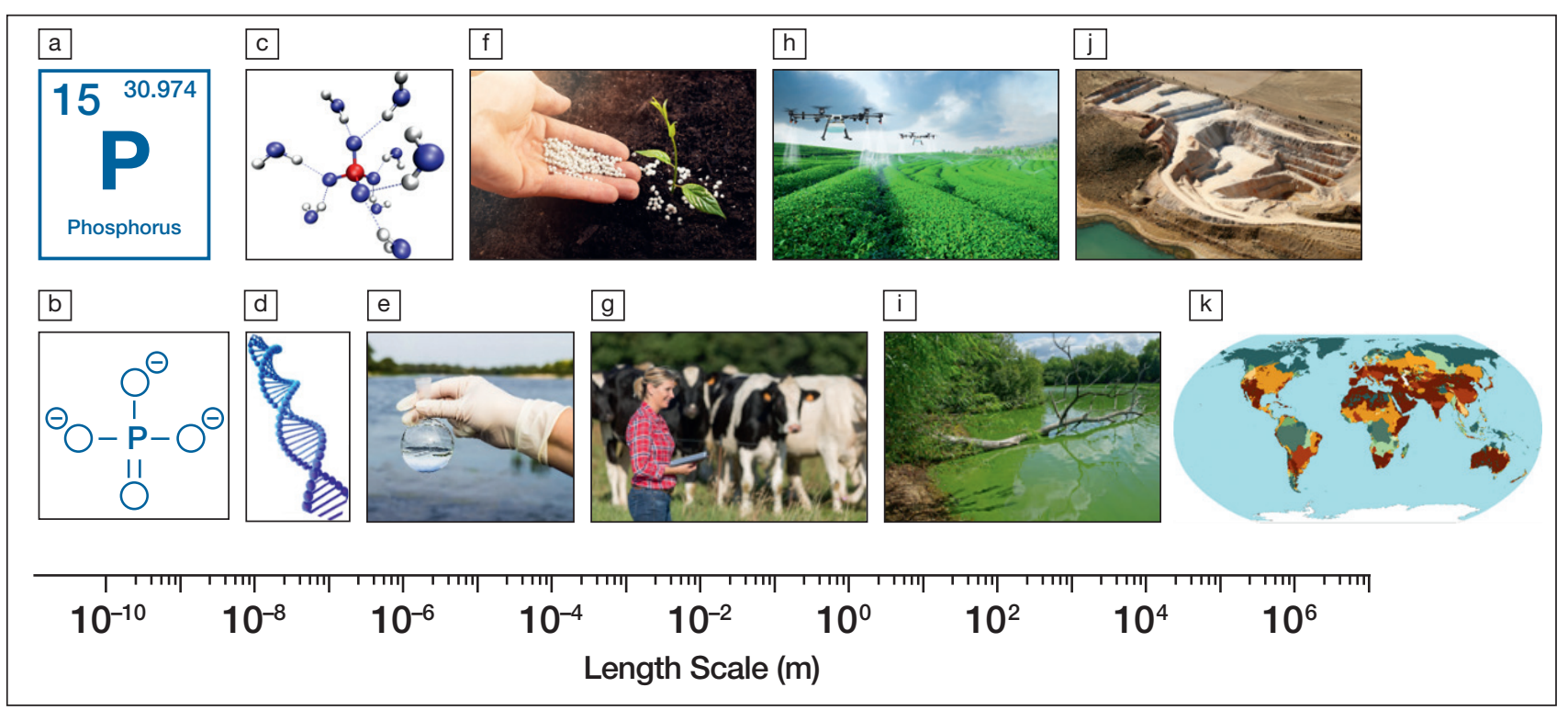

Figure 1. Considerations in the phosphorus life cycle span 17 orders of magnitude in length scale, including (a) elemental $P$, (b) orthophosphates, (c) aqueous orthophosphates, (d) biological molecules such as DNA, (e) water purity, (f) fertilizers, (g) animal farms, (h) agriculture, (i) surface waters, (j) phosphate mines, and (k) geographical considerations, such as economies and politics. Image of phosphate in solution, (c), courtesy of Thomas Hofer. $^{8}$ Global map in $(k)$ shows $P$ water pollution levels across the globe. ${ }^{9}$

result of phosphorus flow into terrestrial and freshwater sources, phosphorus loads are now $400 \%$ greater than preindustrial levels $;{ }^{15}$ the geographical distribution of resulting phosphorus pollution because of human activity (including domestic liquid and solid waste, industrial waste, and agricultural runoff) is shown in Figure $1 \mathrm{k}$. Phosphorus ultimately flows to the oceans, at amounts equal to or greater than $22 \mathrm{Mt} / \mathrm{yr},{ }^{16}$ contributing to more than 400 eutrophication-associated coastal dead zones. ${ }^{17}$

\section{Existing science and technologies}

To promote sustainability of the global phosphorus life cycle, research efforts across many disciplines have focused on phosphorus recovery and/or reuse (i.e., recycling, from food waste, animal and human waste, soils and water). Recovery from surface waters (e.g., lakes and rivers) offers the added benefit of environmental protection or remediation. These technologies are often selected by affordability and, to a materials researcher, may appear as crude or rudimentary relative to the purity and perfection sought in other areas of materials research. ${ }^{4,5}$ An example is a standard treatment process to recover excessive phosphorus from water discharged from point sources such as industrial or municipal treatment plants and animal agriculture involving the precipitation of struvite (magnesium ammonium phosphate, $\mathrm{MgNH}_{4} \mathrm{PO}_{4} \cdot 6 \mathrm{H}_{2} \mathrm{O}$ ). Not only can struvite precipitation treat wastewater, struvite precipitate could potentially be reused as a fertilizer if it meets required fertilizer regulations. However, the struvite precipitation process is inefficient at recovering phosphorus (between $40 \%$ and $90 \%$, depending on the process, the ratio of orthophosphate to organophosphate, and concentrations of phosphorus, ammonia, and magnesium).$^{13}$ Struvite dissolution in agricultural fields is relatively slow; therefore, it is only marginally desired by farmers and is not economically attractive enough to drive widespread adoption.

In freshwater bodies, technologies to reduce aqueous phosphorus concentrations involve adding large amounts of inorganic materials, such as aluminum sulfate $\left(\mathrm{Al}_{2}\left(\mathrm{SO}_{4}\right)_{3}\right.$, or alum) or a lanthanum-modified bentonite mineral (Phoslock), which scavenge orthophosphates from surface water by adsorption and/or precipitation reactions. The solid products of these technologies, some of which contain scarce and undesirable chemical elements (e.g., lanthanum), settle to the bottom of the water body. Not only are the products irrecoverable, the long-term effects of these products are unknown and may significantly alter benthic and aquatic ecosystems. Moreover, there is potential mobilization of the materials, and phosphorus reverts back into the water body with time and changes in water temperature, $\mathrm{pH}$, or dissolved oxygen. These examples illustrate that existing technologies for phosphorus recovery or recycling, more of which are detailed in Reference 13, are too inefficient, too economically disadvantageous, or come with too many uncertain environmental effects to sufficiently address current phosphorus challenges.

\section{Convergence and}

\section{materials research needs}

In some disciplines, phosphorus challenges have been studied for decades, such as earth and environmental sciences and agricultural and biological engineering. However, many more disciplines need to be recruited to address the research issues. With new tools, ideas, and perspectives that have recently emerged, it is timely to converge scientific disciplines to 
address these problems. Impactful solutions to phosphorus challenges require integrated, fundamental research among fields as diverse as materials science and chemistry to crop science and environmental modeling to economics, social sciences, and public policy. Without such integration, even if cost-effective or highperformance technological solutions are developed, society may not adopt these technologies because of social or policy factors. Likewise, inefficient or economically disadvantageous technologies could be adopted because of public policy decisions. In 2017, for example, Germany became the first EU nation to make phosphorus recovery compulsory under law, even though the technologies were not yet economically advantageous. ${ }^{18}$

Other disciplines can guide the priorities of materials researchers, making their contributions more focused and impactful. For example, since methods to reduce food waste could be 80 times more effective than the recycling of food waste, ${ }^{19}$ materials research contributions could include a focus on new food packaging technologies for extended shelf life. It has also been reported that energy consumption and greenhouse gas emissions from current phosphorus recycling technologies may make it less sustainable than originally hoped,$^{20}$ a result that has the potential to undermine available technologies for phosphorus recycling, an example that reinforces the need for total life cycle and technoeconomic assessment.

Within a convergent research environment, fundamental materials research contributions are needed to understand processes that control phosphorus using engineered materials in natural and biological environments - processes such as adsorption/desorption and precipitation/ dissolution driven by (electro)chemical, physical, and biological reactions that occur at the molecular length scale on engineered and natural surfaces (e.g., soil, sediments, wastes). These fundamental interactions are central to higher-level processes and devices (e.g., for wastewater treatment, environmental remediation, and as phosphorus sensors). Ultimately, fundamental research should lead to new technologies and strategies that allow us to control, recover, reuse, and regulate phosphorus.

Data-driven approaches have a significant potential to accelerate discovery, design, and deployment of new materials and processes for phosphorus recovery and reuse. Materials informatics (MI) is a field in which processing-structureproperties-performance relations can be suggested or validated by analyzing large materials data sets with statistical algorithms, many involving aspects of machine learning. In classical areas of materials research, MI has seen a remarkable rate in adoption during the past decade..$^{21-23}$ However, MI approaches for phosphorus recovery and reuse must include additional critical information from outside materials research domains (e.g., life cycle, economic, social, and geospatial information). Organization of disparate databases and formulating descriptors for technologies and processes is perhaps the most impactful challenge in this area. The multiple length scales, distributional nature, and process dependency of many properties complicate the formation and measurement of descriptors for complex materials, processes, and systems. Some guidance may come from previous integration efforts in other informatics fields. ${ }^{24-26}$ Once integrated, multi-objective optimization must help to drive decisions in the presence of tradeoffs between the conflicting objectives of the various stakeholders.

Regional-specific technological solutions will also be required. Geographically specific "local factors" such as hydrology and drainage, soil characteristics, available farm-scale phosphorus management strategies, economics, attitudes, and local environmental policies should be used in materials design and development. ${ }^{4,5}$ These complexities can take informatics and data science approaches, such as multi-criteria decision analysis and decision support tools and systems, well beyond the current MI paradigm and link materials research into broader decision analysis and support tools for social scientists, environmental engineers, and policymakers. ${ }^{27,28}$ Informaticsbased approaches should also include a time-dependent element (e.g., the inclusion of weather forecasts and records, remote sensing, and real-time monitoring data) to understand phosphorus transport pathways as well as to evolve farming attitudes and behaviors.

Using a dynamic phosphorus-informatics framework, new materials technologies can be field-deployed in prototype form, and their performance monitored and evaluated to inform the "iterative" nature of the materials design process. To facilitate data-driven informatics approaches, advanced materials characterization tools will need to be applied to isolate and study phosphorus and phosphorus-containing species in various experiments (e.g., in complex matrices such as wastewater-containing various combinations of living and dead bacteria and their soluble microbial products, plus dissolved organic matter and inorganic ligands and particulates). Techniques such as Raman spectroscopy, $\mathrm{x}$-ray absorption spectroscopy, high-energy $\mathrm{x}$-ray scattering, and electron energy-loss spectroscopy all possess unique abilities to characterize phosphorus at small length scales and in solutions. ${ }^{8,29}$ It will be crucial to use these nanoscale techniques to inform the longer-length-scale regional and global heterogeneities of the problem.

New synthesis strategies and materials architectures should be designed and developed to go beyond large-batch precipitation and particle immersion approaches of the past. Processes and architectures should include those that are deployable for continuous flow processes and for which phosphorus can be recovered from the environment for reuse. ${ }^{4}$ Technologies that can manipulate different forms of phosphorus in soils or emerging biotechnology applications (e.g., algae technology, hydroponics) should be pursued, specifically those that can turn bio-inaccessible forms into bioaccessible forms and keep phosphorus molecularly mobilized yet spatially confined for plant use. ${ }^{30}$ New opportunities could be explored to use interfaces and thin films to reduce materials cost, to deposit functional materials on novel substrates such as highly porous or fibrous materials to be used as filters or 
recoverable products, and to use highly absorbent materials such as hydrogels.

Recovered phosphorus from food waste, animal and human waste, soils, and water could also be repurposed for use in, or as starting materials for, other non-agricultural products that help to transition society from a linear phosphorus economy (consumption) to a circular phosphorus economy. ${ }^{31,32}$ Materials research could play a central role in boosting bio-based economies by developing new applications for recycled phosphorus outside of the agricultural domain. Examples of such applications include new biomaterials, biochemicals, biopolymers, fibers, and 2D materials for applications as diverse as energy conversion and storage to biomedical engineering. New materials applications that use recycled phosphorus could create new value chains that change the economics and utilization of phosphorus recovery processes.

Though it is uncertain how the phosphorus life cycle will change in the coming decades, it will be very different from today. Materials research is central to helping society through this transition, from the design and development of new recovery technologies and processes to the deployment of new materials and devices that use recovered phosphorus and, thereby, reinforcing a more circular bioeconomy. Materials researchers have most, if not all, of the necessary tools (e.g., state-of-the-art electron microscopes, X-ray spectroscopes, and MI infrastructure) for making these contributions. However, materials researchers alone cannot create solutions that have a significant and positive impact on the phosphorus life cycle. Convergent research teams, integrating their disciplinary contributions, will be critical to creating solutions that are efficient, effective, economically viable, and that ultimately will be adopted by farmers, environmental engineers, and policymakers. This high degree of collaborative work is specific and compelling, exemplary of convergence research. Phosphorus has evolved into an element on which society depends for sustenance and is in need of critical contributions from materials researchers.

\section{References}

1. A. Sharpley, H. Jarvie, D. Flaten, P. Kleinman, J. Environ. Qual. 47, 774 (2018).

2. I. Amato, MRS Bull. 20, 101 (1995).

3. D. Cordell, J.-0. Drangert, S. White, Glob. Environ. Change 19, 292 (2009).

4. B.E. Rittman, B. Mayer, P. Westerhoff, M. Edwards, Chemosphere 84, 846 (2011).

5. B.K. Mayer, L.A. Baker, T.H. Boyer, P. Drechsel, M. Gifford, M.A. Hanjra, P. Parameswaran, J. Stoltzfus, P. Westerhoff, B.E. Rittmann, Environ. Sci. Technol. 50, 6606 (2016).

6. B. Jacobs, D. Cordell, J. Chin, H. Rowe, Environ. Sci. Policy 77, 151 (2017).

7. M.V. Chester, B. Allenby, Elem. Sci. Anth. 7, 21 (2019).

8. I. Persson, M. Trublet, W. Klysubun, J. Phys. Chem. A 122, 7413 (2018).

9. M.M. Mekonnen, A.Y. Hoekstra, Water Resour. Res. 54, 345 (2018).

10. US Geological Survey, Mineral Commodity Summaries (Feb. 2019), https://www.usgs.gov/centers/ nmic/phosphate-rock-statistics-and-information.

11. G.R. Matos, US Geological Survey Data Series 896 (2015), http://dx.doi.org/10.3133/ds896 (accessed September 30, 2019).

12. S.W. Cordell, Annu. Rev. Environ. Resour. 39, 161 (2014).

13. E. Desmidt, K. Ghyselbrecht, Y. Zhang, L. Pinoy, B. Van der Bruggen, W. Verstraete, K. Rabaey, B. Meesschaert, Crit. Rev. Environ. Sci. Technol. 45 , 336 (2015).

14. S.L. Foster, S.I. Perez Bakovic, R.D. Duda, S. Maheshwari, R.D. Milton, S.D. Minteer, M.J. Janik, J.N. Renner, L.F. Greenlee, Nat. Catal. 1, 490 (2018).

15. P. Falkowski, R.J. Scholes, E. Boyle, J. Canadell, D. Canfield, J. Elser, N. Gruber, K. Hibbard, P. Högberg, S. Linder, F.T. Mackenzie, B. Moore III, T. Pedersen,
Y. Rosenthal, S. Seitzinger, V. Smetacek, W. Steffen, Science, 290, 291 (2000)

16. M. Bennett, S.R. Carpenter, N.F. Caraco, BioScience 151, 227 (2001)

17. R.J. Diaz, R. Rosenberg, Science 321, 926 (2008).

18. R.W. Scholz, F.-W. Wellmer, J. Ind. Ecol. 23, 313 (2019).

19. D.A. Vaccari, S.M. Powers, X. Li, Environ. Sci. Technol. 53, 10417 (2019).

20. S.R. Golroudbary, M.E. Wali, A. Kraslawski, Sci. Total Environ. 672, 515 (2019).

21. J. Hill, G. Mulholland, K. Persson, R. Seshadri, C. Wolverton, B. Meredig, MRS Bull. 41, 399 (2016).

22. R. Ramprasad, R. Batra, G. Pilania, A. MannodiKanakkithodi, C. Kim, npj Comput. Mater. 3, 54 (2017).

23. J.S. Peerless, N.J.B. Milliken, M.D. Manning, T.J. Oweida, Y.G. Yingling, Adv. Theory Simul. 2 1800129 (2019)

24. S. Karcher, E.L. Willighagen, J. Rumble, F. Ehrhart, C.T. Evelo, M. Fritts, S. Gaheen, S.L. Harper, M.D. Hoover, N. Jeliazkova, N. Lewinski, R.L. Marchese Robinson, K.C. Mills, A.P. Mustad, D.G. Thomas, G. Tsiliki, C.0. Hendren, Nanolmpact 9, 85 (2018).

25. A. Holzinger, I. Jurisica, in Interactive Knowledge Discovery and Data Mining in Biomedical Informatics. Lecture Notes in Computer Science, A. Holzinger, I. Jurisica, Eds. (Springer, Berlin, Germany, 2014), vol. 8401.

26. R.B. Squires, J. Noronha, V. Hunt, A. Garcia-Sastre, C. Macken, N. Baumgarth, D. Suarez, B.E. Pickett, Y. Zhang, C.N. Larsen, A. Ramsey, L. Zhou, S. Zaremba, S. Kumar, J. Deitrich, E. Klem, R.H. Scheuermann, Influenza Other Respir. Viruses 6, 404 (2012).

27. R.L. Church, A.T. Murray, M.A. Figueroa, K.H. Barber, Eur. J. Oper. Res. 121, 247 (2000).

28. P.J. Drohan, M. Bechmann, A. Buda, F. Djodjic, D. Dooddy, J.M. Duncan, A. Iho, P. Jordan, P.J. Kleinman, R. McDowell, P.-E. Mellander, I.A. Thomas, P.J.A. Withers, J. Environ. Qual. 48, 1218 (2019).

29. W.W. Rudolph, G. Irmer, Appl. Spectrosc. 61, 1312 (2007).

30. M. Li, J. Liu, Q. Zhou, M. Gifford, P. Westerhoff, J. Cleaner Prod. 217, 127 (2019).

31. P. Jarvie, D. Flaten, A.N. Sharpley, P.J.A. Kleinman, M.G. Healy, S.M. King, J. Environ. Qual. 48, 1145 (2019).

32. B. Geissler, L. Hermann, M.C. Mew, G. Steiner, Minerals (Basel) 8, 395 (2018).

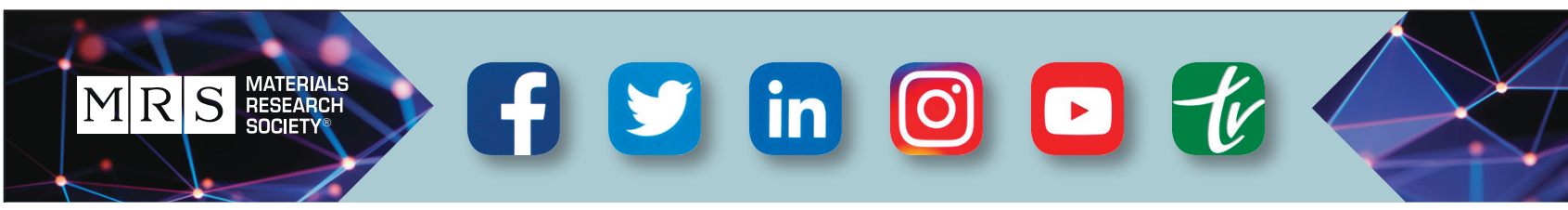

